\section{STUDIES ON THE ECOLOGY OF THE RAFT SPIDER DOLOMEDES FIMBRIATUS (DOL.) (ARANEAE: PISAURIDAE) IN THE RICE FIELDS OF COIMBATORE}

\section{Ganesh Kumar, M.P.Sugumaran, K. Sivasubramanian and B. Nagamani}

Department of Environmental Sciences, Tamil Nadu Agricultural University, Coimbatore, Tamil Nadu 641003, India

During the past decade there has been increased interest in using natural enemies, notably predators for the regulation of insect pests of different crops. This has been more so in the case of rice insects. An impressive array of natural enemies has been recorded attacking different rice pests in India (Gunathilagaraj \& Ganesh Kumar, 1997). During 1991-94 surveys on the population of spiders in rice fields and border weeds were conducted using sweep net which yielded the presence of 17 species of spiders from the rice fields and border weeds of Tamil Nadu. However, our current investigations revealed the existence of one more species of spider, Dolomedes fimbriatus (Dol.) which had so far escaped our observations. This was probably due to the habitat of the spider which may not easily get trapped in a sweep net as it is usually found either on water or very close to the water surface with its legs resting on the surface of the water. D. fimbriatus (Dol.) belongs to one group of spiders that is rarely observed far from the moist edges of streams and lakes, and that includes some members wonderfully adapted for life near or on the water surface. Our investigations regarding the essentially amphibious nature of this spider was proven by the fact that all the specimens which were collected and maintained in the laboratory with grasshopper nymphs failed to survive beyond a week. This happened even though water was provided in the form of a wet cotton swab. This prompted us to maintain the spider in an aquarium. These spiders resemble the wolf spiders closely in appearance but differ from them quite distinctly in certain habits. The most appropriate appellation is that of "fisher spider"-a name that properly conveys their amphibious nature as well as their occasional fondness for little fishes.

The typical fisher spider of the genus Dolomedes (Doleschall) is a grey or brown spider with an oval abdomen and a longitudinal cephalothorax more flattened than in most wolf spiders. The integument bears many appressed plumose hairs, in addition to various simple hairs and spines. The eyes have much the same

Received 2 December 1998; Accepted 4 March 1999 arrangement as in the family Lycosidae but the dorsal row of four is not so strongly curved, and rarely is markedly larger than the front row. This would seem to indicate that the range and acuity of the fisher's eyes are less than those of the typical wolves. They are big-eyed hunters, nevertheless, and seem to have excellent day vision. $D$. fimbriatus is a dark brown species with a pair of cream bands running along the sides of the cephalothorax and continuing along the flanks of the abdomen. There is very little patterning on the body, the spider being very robust with thick strong legs. The female is about $22 \mathrm{~mm}$ long while the male is about $15 \mathrm{~mm}$. The eight simple eyes are arranged in two strongly recurved rows. The anterior eye row is shorter than the posterior eye row. The sternum is yellow, as wide and clothed with brown erect hairs.

In our observations $D$. fimbriatus was found to be capable of swimming inside water over considerable distances before coming to rest either on the walls of the aquarium or on the roots of Pistia which were provided (Figure 2). The aquatic pisaurids are able to remain beneath the water for long periods as was found in our investigations. Gertsch (1979) has also reported one instance of forty-five minutes as the limit to which Dolomedes could remain submerged under water. We timed the limit of submergence for 10 consecutive days using a stop watch. From our observations we found that the spider was able to remain submerged for a maximum of five hours 36 minutes and 25 seconds (Table 1). The body hairs capture bubbles of air, and as some of the bubbles come in contact with the respiratory orifices, they get the much needed oxygen for their underwater sallies. This gives the body a silvery sheen when the spider remains submerged (Figure 1).

All the species coming under the genus Dolomedes live in marshy and swampy areas, usually spending their day sitting upon a floating leaf or some aquatic plant (Figure 2). On closer examination it will be seen that the spider keeps its forelegs in contact with the surface of the water (Figure 2), where they are in position to detect vibrations set up by a small fish swimming or an insect struggling on the water surface. The bulk of the food of these spiders undoubtedly consists of terrestrial insects from the vegetation around the pool, which have accidentally fallen into the water as well as aquatic insects which have come to lay their eggs in the pool. Diving below the surface to catch prey is not a normal method for Dolomedes spiders, which being large, have to make considerable effort to break the water's surface film and can submerge only by thrusting against some anchored support with their backlegs like a floating plant or from the walls of the aquarium as we observed in numerous instances. Though there have been several reports of these spiders catching small fish and tadpoles (Gertsch, 1979; Mafham \& Mafham, 1983) the spider was found fish fry which we provided in the aquarium. Under submerged conditions, we found fish fry which were inquisitive enough to venture near the spider were studiously ignored. However though we were unable to photograph the actual capture of fish, on two occasions we came across the spider feeding on fish while resting on the 
sides of the aquarium. The entire body was reduced to a ball of undigested material. Mafham and Mafham (1983) reported that the strong jaws and potent venom can rapidly overcome vertebrate prey, which is effectively digested by the spider's juices. Mafham and Mafham (1983) have also reported that some fisher spiders actually attract prey within reach by sitting on a floating leaf in the normal way with their legs dabbling gently in the water. Like the wriggling of an angler's worm, the movements attract small fishes where the spider can pounce on them using the excellent eyesight it has. The egg sac is white and carried by means of chelicerae (Figure 3). We observed the spider diving into the water along with the egg sac but after the formation of the egg sac, the forays into water were not so common. Just before hatching, a loose web at the edge of the aquarium was constructed. The spiderlings which hatched out remained for two days in the web before dispersing. Dispersal was by ballooning as in the case of other species.

\section{References}

Gertsch, W.J.G. (1979) American Spiders. New York. Van Nostrand Reinhold. Co. 273pp.

Gunathilagaraj, K. and Ganesh Kumar, M. (1997) Natural en-emies of rice insects. Madras agric. J. 84 :395-431.

Mafham, RP. and Mafham, K.P. (1983) Spiders of the World. UK. Blandford. 191pp.

Table 1. Time taken by Dolomedes fimbriatus to remain sub-merged

\begin{tabular}{ll}
\hline Day & Time $(\mathrm{Hr}:$ Min:Sec) \\
\hline 1. & $0: 25: 02$ \\
2. & $02: 45: 22$ \\
3. & $0: 14: 06$ \\
4. & $0: 19: 05$ \\
5. & $05: 36: 25$ \\
6. & $01: 16: 40$ \\
7. & $0: 40: 36$ \\
8. & $0: 33: 27$ \\
9. & $0: 27: 32$ \\
10. & $0: 42: 12$ \\
\hline
\end{tabular}

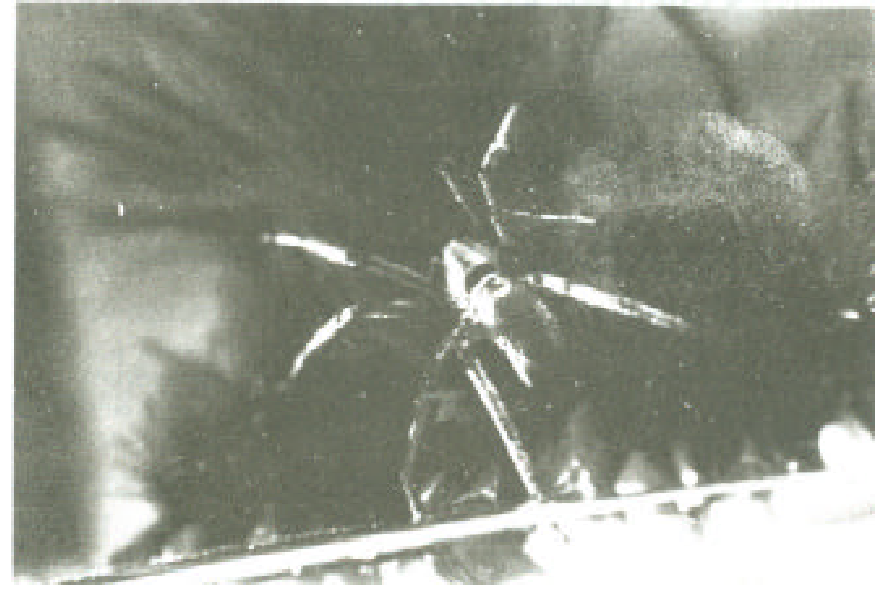

Figure 1. Dolomedes fimbriatus under water on roots of Pistia sp.

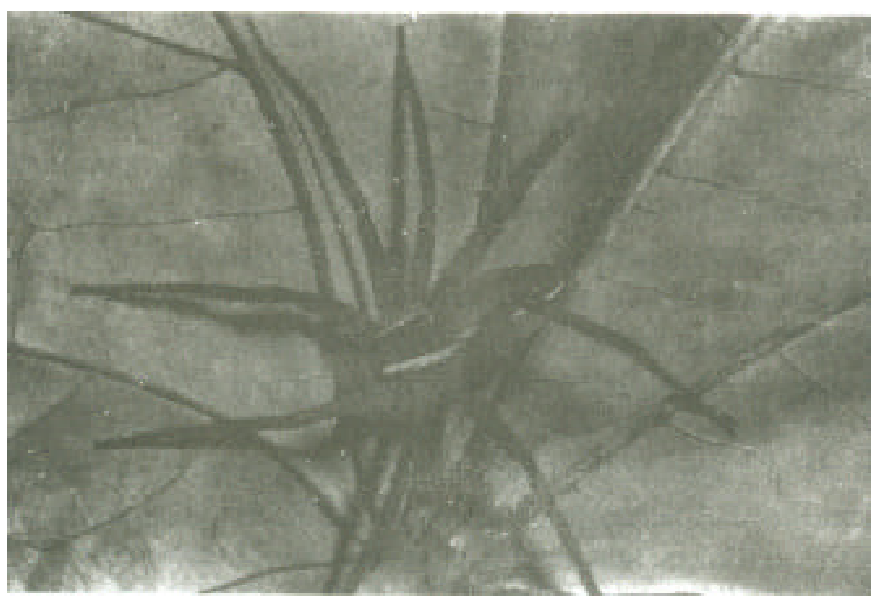

Figure 2. Dolomedes fimbriatus adult female on a floating leaf

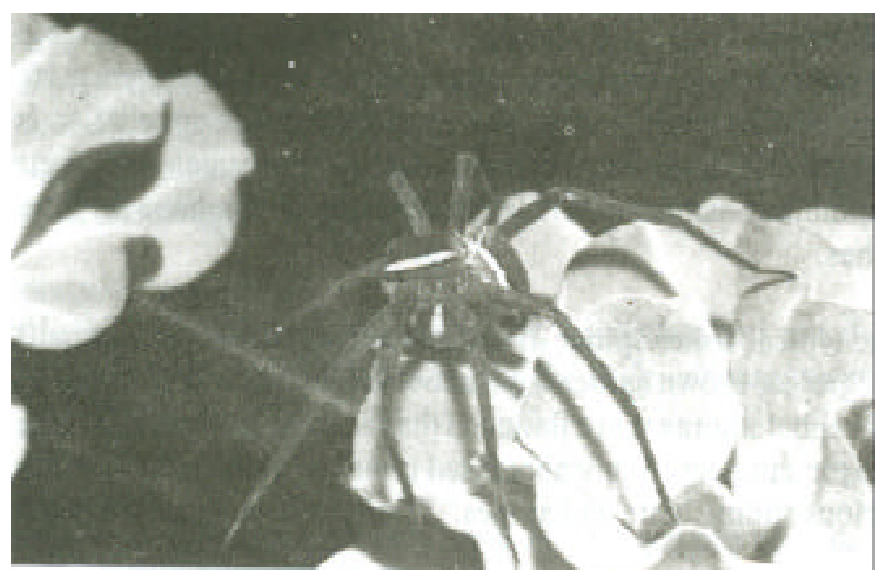

Figure 1. Dolomedes fimbriatus female with egg sac on Pistia sp. 